\section{Response to: 'Correspondence to 'Associations of regular glucosamine use with all-cause and cause-specific mortality: a large prospective cohort study' by Li et al' by Yueh et al}

As suggested by Yueh et $a l,{ }^{1}$ it is important to present factors such as dosage, frequency and treatment adherence, which may make confounded dose-response effects. However, as explained at length in the limitation section, ${ }^{2}$ the UK Biobank did not gather detailed information on the dosage, forms or duration of glucosamine use to perform further analyses on the dose relationship of glucosamine with the mortality, like Simon et al. ${ }^{3}$ And the data collection on dietary supplements intake was not conducted in clinical settings in order to promote more truthful reporting. Further studies are necessary to better clarify the dose-relationship of glucosamine use with the mortality.

Yueh et al ${ }^{1}$ mentioned that some residual confounders would have to be strongly related to HRs of mortality, such as stress, air pollution, and nutrition status. According to the published literature, ${ }^{4-6}$ a total of 27 confounders, the most important risk factors for mortality, were included in our fully adjusted models, among which depression status reflects stress, as well as Townsend Deprivation Index, body mass index and the use of various drugs reflect nutritional status to some extent. Actually, we also evaluated the impact of air pollution, including nitrogen oxides and particulate matter, on the relationship between glucosamine and mortality, and found that the results did not vary substantially. Due to the hard limit on word count of the manuscript required by the journal, the content for the impact of air pollution on results was not included in the manuscript.

Obviously, with the current observational study design, the possibility of residual confounding due to imprecise measurements or unknown factors cannot be excluded for all findings in our study, despite our careful adjustment of all measured confounders. ${ }^{2}$ Negative controls may be an effective tool for detecting confounding and bias in observational studies. ${ }^{7}$ Future studies with negative control design are necessary to improve causal inference, as the Yueh et al suggested. ${ }^{1}$

In regard to the question of the bias of confounding by healthy lifestyle, we acknowledged that regular glucosamine use may be a marker for a healthy lifestyle, as the results of our study showed, compared with non-users, glucosamine users were more likely to be current non-smokers and more physically active. ${ }^{2}$ However, it is difficult to disentangle the effects of a healthy lifestyle from the use of glucosamine in an observational study, although the potential confounders were carefully adjusted in our analyses. We also clarified this issue in the limitations of the manuscript. ${ }^{4}$

Finally, glucosamine is also used to treat patients with arthritis, which might lead to underestimation of the protective effect of glucosamine due to the poor prognoses of arthritic patients. Therefore, we have included arthritis in the fully adjusted models in our study. In addition, we conducted additional subgroup analysis to assess potential modification effect by modelling the cross-product term of arthritis (yes or no) with glucosamine use in the fully adjusted model, and found that the associations of glucosamine use with all-cause and cause-specific mortality were not significantly modified by arthritis.

Zhi-Hao Li, Wen-Fang Zhong, Qing-Mei Huang, Xi-Ru Zhang, Chen Mao ㅇ Department of Epidemiology, School of Public Health, Southern Medical University, Guangzhou, Guangdong, China

Correspondence to Professor Chen Mao, School of Public Health, Southern Medical University, Guangzhou 510515, China; maochen9@smu.edu.cn

Contributors Z-HL, W-FZ, Q-MH, X-RZ and CM wrote the manustrcipt.

Funding The authors have not declared a specific grant for this research from any funding agency in the public, commercial or not-for-profit sectors.

Competing interests None declared.

Patient and public involvement Patients and/or the public were not involved in the design, or conduct, or reporting, or dissemination plans of this research.

Patient consent for publication Not required.

Provenance and peer review Commissioned; internally peer reviewed.

(c) Author(s) (or their employer(s)) 2020. No commercial re-use. See rights and permissions. Published by BMJ.

\section{Check for updates}

To cite Li Z-H, Zhong W-F, Huang Q-M, et al. Ann Rheum Dis Epub ahead of print: [please include Day Month Year]. doi:10.1136/annrheumdis-2020-218659

Received 21 July 2020

Accepted 22 July 2020

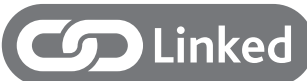

- http://dx.doi.org/10.1136/annrheumdis-2020-218486

Ann Rheum Dis 2020;0:1. doi:10.1136/annrheumdis-2020-218659

ORCID iD

Chen Mao http://orcid.org/0000-0002-6537-6215

\section{REFERENCES}

1 Yueh H-Z, Yeh C-J, JC-C W. Correspondence to 'Associations of regular glucosamine use with all-cause and cause-specific mortality: a large prospective cohort study' by Li et al. Ann Rheum Dis 2020. doi: 10.1136/annrheumdis-2020-218486

2 Li Z-H, Gao X, Chung VC, et al. Associations of regular glucosamine use with allcause and cause-specific mortality: a large prospective cohort study. Ann Rheum Dis 2020;79:829-36.

3 Simon TG, Duberg A-S, Aleman S, et al. Association of aspirin with hepatocellular carcinoma and Liver-Related mortality. N Eng/ J Med 2020;382:1018-28.

4 Kantor ED, Lampe JW, Navarro SL, et al. Associations between glucosamine and chondroitin supplement use and biomarkers of systemic inflammation. J Altern Complement Med 2014:20:479-85.

$5 \mathrm{Ma} \mathrm{H}$, Li X, Sun D, et al. Association of habitual glucosamine use with risk of cardiovascular disease: prospective study in UK Biobank. BMJ 2019;365:11628.

6 Bell GA, Kantor ED, Lampe JW, et al. Use of glucosamine and chondroitin in relation to mortality. Eur J Epidemiol 2012;27:593-603.

7 Lipsitch M, Tchetgen Tchetgen E, Cohen T. Negative controls: a tool for detecting confounding and bias in observational studies. Epidemiology 2010;21:383-8. 